\title{
Type I collagen content is increased in lungs of patients with adult respiratory distress syndrome
}

\author{
JEROLD A LAST, ALLAN D SIEFKIN, KAREN M REISER \\ From the Department of Internal Medicine and California Primate Research Center, University of California, \\ Davis, California, USA
}

ABSTRACT Collagen in lung tissue was examined from patients with adult respiratory distress syndrome, from patients who did not have this disease but required mechanical ventilation and oxygen treatment, and from patients without overt lung disease. Cyanogen bromide peptide mapping techniques were used to determine the ratio of type I to type III collagen present in these lungs. In the fibrotic lungs from patients with adult respiratory distress syndrome a shift was found in the ratio of type I to type III from the normal value of $2: 1$ to a mean value of $3 \cdot 4: 1$. In patients with normal lungs and those with other lung diseases collagen type ratios were normal. Our data suggest that (i) changes in lung collagen of patients with adult respiratory distress syndrome resemble those previously described in patients with idiopathic pulmonary fibrosis, although the changes occur much more rapidly in the former; (ii) the increased content of collagen in lungs of patients with adult respiratory distress syndrome shown by others is predominantly of type I collagen; and (iii) the stimulus to the lung to produce excess type I collagen relative to type III is not solely of iatrogenic origin-that is, resulting from oxygen or ventilator treatment.

The adult respiratory distress syndrome is a devastating disease of diverse causes in which a previously normal lung can be transformed into an irreversibly fibrotic one in a few weeks. The triggering mechanism for the fibrotic process remains unknown, although considerable controversy centres on the relative roles of the underlying disease process and of treatment with oxygen and positive endexpiratory pressure, which are often used to sustain life during the acute phase.$^{1-4}$ Serious derangements in collagen metabolism can occur extremely rapidly in the course of this disease. Zapol and coworkers ${ }^{5}$ have shown that the total lung collagen content is significantly increased as early as 12 days after its clinical onset. Many workers have shown histological evidence of rapid collagen deposition in lungs of patients with the adult respiratory distress syndrome. ${ }^{1-36}$ The great rapidity of the change is remarkable ${ }^{3}$ as diffuse pulmonary fibrosis is usually thought of as a chronic disease of insidious onset. ${ }^{7}$

Several animal models of acute respiratory disease leading to pulmonary fibrosis within two to four

Address for reprint requests: Dr JA Last, Department of Internal Medicine and California Primate Research Center, University of California, Davis, CA 95616, USA.

Accepted 19 January 1983 weeks have become available recently. The best characterised of these models of the adult respiratory distress syndrome include disease induced in rodents by intratracheally instilled bleomycin, ${ }^{89}$ intraperitoneally injected paraquat, ${ }^{10}$ and inhaled ozone. ${ }^{112}$ In each of these three animal models not only is the total lung collagen content increased in parallel with the development of pulmonary fibrosis $^{913}$ but also there are qualitative changes in the types of collagen being synthesised by the lung after the insult. ${ }^{11}$ These shifts in collagen types parallel the changes previously reported in lungs of patients with idiopathic pulmonary fibrosis, ${ }^{14}$ and may reflect an obligatory basic mechanism. In the light of the data from the animal models of this disease we were stimulated to examine the question raised recently by Hempel and Lenfant ${ }^{15}$ of whether the chemical composition of collagen synthesised in animal models of pulmonary fibrosis is similar to that of the collagen synthesised and accumulated in lungs of patients with the adult respiratory distress syndrome. We know of no comparable study.

\section{Methods}

THE PATIENTS 364

Three groups of patients were selected for this 
study. The first group consisted of patients with clinically defined adult respiratory distress syndrome; the key clinical criteria were increasing dyspnoea, tachypnoea, severe hypoxaemia despite oxygen and positive end-expiratory pressure, and a chest radiograph showing diffuse pulmonary infiltration or "white-out." At necropsy (or, in one case, biopsy) histological findings of hyaline membrane formation and diffuse interstitial fibrosis confirmed the clinical impression of the adult respiratory distress syndrome. The second group of patients required mechanical ventilation and oxygen treatment for conditions other than the adult respiratory distress syndrome; the clinical diagnoses were confirmed at necropsy. The third group consisted of patients with no known lung disease who had not required mechanical ventilation or high concentrations of inspired oxygen. Table 1 summarises characteristics of the patients, including sex, age, final diagnosis, and smoking history. Table 2 summarises their treatment, including the number of days on a ventilator, the highest positive end-expiratory pressure used, and the highest oxygen concentration required. Groups 1 and 2 both contained smokers and non-smokers, both men and women, and were reasonably well matched for age (mean age of group $1=63 \pm 8$ years; group $2=69 \pm 6$ years without case $6,58 \pm 23$ years with case 6 included).

All lung samples were obtained at necropsy, except for one obtained at open lung biopsy. The protocol was approved by the Institutional Committee on Ethics of Human Experimentation. All samples were immediately frozen until assayed. Samples were coded, and the investigator performing the assays did not know the diagnosis at the time that the assays were conducted.

We obtained some preliminary data on lung collagen concentration and wet-to-dry weight ratio for three patients with adult respiratory distress syndrome and two from the group of control patients who had not received artificial ventilation. Hydroxyproline was measured by the Woessner assay. ${ }^{17}$

\section{QUANTITATION OF COLLAGEN TYPES}

We used cyanogen bromide peptide mapping to quantitate collagen types ratios, as previously described, ${ }^{116}$ with minor modifications. Stock

Table 1 Clinical history of the patients with adult respiratory distress syndrome (ARDS)

\begin{tabular}{|c|c|c|c|c|c|}
\hline Group & $\begin{array}{l}\text { Patient } \\
\text { No }\end{array}$ & Sex & Age (y) & Final diagnosis & $\begin{array}{l}\text { Smoking } \\
\text { (pack-years) }\end{array}$ \\
\hline \multirow[t]{3}{*}{1} & 1 & $\mathbf{F}$ & 52 & $\begin{array}{l}\text { ARDS, Gram(-) sepis, Gram(-) pneumonia, } \\
\text { renal disease }\end{array}$ & 0 \\
\hline & $\begin{array}{l}2 \\
3\end{array}$ & $\begin{array}{l}\mathbf{M} \\
\mathbf{M}\end{array}$ & $\begin{array}{l}64 \\
65\end{array}$ & $\begin{array}{l}\text { ARDS, pneumonia } \\
\text { ARDS, intra-abdominal bleeding, portal } \\
\text { hypertension }\end{array}$ & $\begin{array}{r}30 \\
0\end{array}$ \\
\hline & $\begin{array}{l}4 \\
5\end{array}$ & $\mathbf{M}$ & $\begin{array}{l}71 \\
76\end{array}$ & ARDS, Gram(-) sepsis, diabetes, pneumonia & $\begin{array}{r}? \\
30\end{array}$ \\
\hline 2 & $\begin{array}{l}5 \\
6 \\
7\end{array}$ & $\begin{array}{l}\mathbf{M} \\
\mathbf{F} \\
\mathbf{M}\end{array}$ & $\begin{array}{l}76 \\
25 \\
65\end{array}$ & $\begin{array}{l}\text { Pneumonia, Gram(-) sepsis, pleural etrusion } \\
\text { Lupus, septic shock, renal failure } \\
\text { Congestive heart failure, arrhythmia }\end{array}$ & $\begin{array}{r}>30 \\
>70\end{array}$ \\
\hline 3 & $\begin{array}{r}8 \\
9 \\
10\end{array}$ & $\begin{array}{l}\mathbf{M} \\
\mathbf{M} \\
\mathbf{M}\end{array}$ & $\begin{array}{l}20 \\
71 \\
41\end{array}$ & $\begin{array}{l}\text { Trauma (motorcycle) } \\
\text { Cerebrovascular accident, alcoholic cirrhosis } \\
\text { Haemophilia, exsanguination }\end{array}$ & $?$ \\
\hline
\end{tabular}

Table 2 Treatment and outcome: lung collagen of patients studied

\begin{tabular}{|c|c|c|c|c|c|c|}
\hline Group & Patient No & $\begin{array}{l}\text { Days on } \\
\text { ventilator }\end{array}$ & Highest PEEP & $F_{1} O_{2}$ attained & Type III collagen (\%*) & $\begin{array}{l}\text { Type I:III collagen } \\
\text { ratio }\end{array}$ \\
\hline 1 & $\begin{array}{l}1 \\
2 \\
3 \\
4\end{array}$ & $\begin{array}{l}18 \\
12 \\
15 \\
14\end{array}$ & $\begin{array}{r}0 \\
15 \\
8 \\
5\end{array}$ & $\begin{array}{r}40-100 \\
40-100 \\
100 \\
100\end{array}$ & $\begin{aligned} & 20,23,26(23) \\
& 25(25) \\
& 23,22(22 \cdot 5) \\
& 21,23(22) \\
& \text { Group mean } 23 \cdot 1 \dagger\end{aligned}$ & $\begin{array}{l}3 \cdot 3: 1 \\
3 \cdot 0: 1 \\
3 \cdot 4: 1 \\
3 \cdot 5: 1 \\
3 \cdot 4: 1\end{array}$ \\
\hline 2 & $\begin{array}{l}5 \\
6 \\
7\end{array}$ & $\begin{array}{l}8 \\
5 \\
3\end{array}$ & $\begin{array}{l}5-8 \\
5-12 \\
5-8\end{array}$ & $\begin{array}{l}50-100 \\
35-100 \\
60-70\end{array}$ & $\begin{array}{l}34,36(35) \\
32,33,33(32 \cdot 7) \\
34,35,36(35) \\
\text { Group mean } 34 \cdot 2\end{array}$ & $\begin{array}{l}1 \cdot 9: 1 \\
2 \cdot 1: 1 \\
1 \cdot 9: 1 \\
1 \cdot 9: 1\end{array}$ \\
\hline 3 & $\begin{array}{r}8 \\
9 \\
10\end{array}$ & $\begin{array}{l}0 \\
0 \\
0\end{array}$ & & & $\begin{array}{c}34,33(33 \cdot 5) \\
32,35,36(33 \cdot 7) \\
30,31(30 \cdot 5) \\
\text { Group mean } 32 \cdot 6\end{array}$ & $\begin{array}{l}2 \cdot 0: 1 \\
1 \cdot 9: 1 \\
2 \cdot 3: 1 \\
2 \cdot 0: 1\end{array}$ \\
\hline
\end{tabular}

PEEP-positive end-expiratory pressure; $F_{1} \mathrm{O}_{2}$-inspired concentration of oxygen.

* Data from individual lung samples shown; each number represents the average of two gel scans. The mean of the individual determinations is shown in parentheses.

† Group 1 was significantly different from groups 2 and $3(p<0-29)$ by the Wilcoxon (Mann-Whitney) test. 
cyanogen bromide was stored in acetonitrile $(2 \mathrm{~g} / \mathrm{ml})$ at $-70^{\circ} \mathrm{C}$; aliquots were thawed as needed. Either two or three samples from each patient were analysed; they were taken from different lobes when possible. Sample sizes ranged from 2 to $5 \mathrm{~g}$, thus permitting multiple determinations to be made from one sample if necessary. In the case of the biopsy material (patient 2 ), there was only enough tissue for one determination. The samples were homogenised and washed overnight in $50 \mathrm{~mol} / \mathrm{l}$ trishydrochloride, $\mathrm{pH} 7 \cdot 4$, to remove non-collagenous proteins. The samples were then digested with cyanogen bromide $(1.5 \times$ weight of sample $)$ in $70 \%$ formic acid under nitrogen for four hours at $37^{\circ} \mathrm{C}$. Cyanogen bromide and formic acid were removed by rotary evaporation; the samples were rinsed with distilled water three times, dissolved in column start-

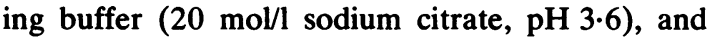
centrifuged to remove undigested tissue. The peptides were then separated by chromatography on carboxymethyl cellulose as previously described. The fractions from the peak containing the peptides $\alpha_{1}$ (I)CB-8, $\alpha_{1}$ (I)CB-3-8, and $\alpha_{1}$ (III)CB-8 were pooled and dialysed, and electrophoresis was performed on a polyacrylamide gel. ${ }^{16}$ The Coomassieblue-stained gel was scanned with a densitometer equipped with an integrator to obtain the ratios of collagen types. We also measured total hydroxyproline $^{17}$ in the lung homogenate before cyanogen bromide digestion and in the clarified sample to determine the approximate percentage digestion of the total collagen present in the lung sample.

We found that in lung tissue from younger patients we routinely solubilised $80 \%$ or more of the lung tissue with a single digestion. A single digestion of lung tissue from older patients (aged 50 years and over), however, did not solubilise more than 50 $60 \%$ of the total hydroxyproline. We therefore redigested the insoluble pellet from several different patients and determined the ratio of collagen types in the second digest (about $60 \%$ yield of the remaining 4-hydroxyproline in the pellets). We found that a second digestion solubilised about the same percentage of the total hydroxyproline as did the first digestion; furthermore, the ratio of collagen types in the pellet was identical to the ratio found in the initial digestion. Thus cyanogen bromide did not preferentially solubilise one type of collagen in such digests despite the relatively low yield of cyanogen bromide peptides solubilised at this step in the lungs from older subjects.

\section{HISTOLOGY}

Microscopic evaluation of lung tissue, with haematoxylin and eosin staining of $6-\mu \mathrm{m}$ paraffin sections, was routinely performed at necropsy. In
Table 3 Apparent collagen concentrations in lungs from patients studied

\begin{tabular}{llll}
\hline Patient No & Group & $\begin{array}{l}\text { Wet-to-dry } \\
\text { weight ratio }\end{array}$ & $\begin{array}{l}\mu g \text { hydroxy- } \\
\text { prolinelg } \\
\text { dry lung }\end{array}$ \\
\hline 1 & 1 & 3.6 & 2.6 \\
3 & 3.9 & 7.9 \\
Group mean & & $\frac{4.0}{5.8}$ & $\overline{5.0} \pm 2.7$ \\
8 & 3 & 2.9 & 1.9 \\
9 & & 2.5 & 1.2 \\
Group mean & $\overline{2.7}$ & $-1.6 \pm 0.4$ \\
\hline
\end{tabular}

addition, in some cases further sections were stained with Masson's trichrome to visualise collagen.

\section{Results}

Ratios of collagen types in lung samples from the patients in the study are given in table 2. Normal lung contains about $33 \%$ type III collagen according to our observations ${ }^{11}$ and those of others. ${ }^{14}$ The only patients with a shift in the ratios of collagen types were the four who had the adult respiratory distress syndrome, who all showed an increase in type I relative to type III collagen. There was little variation among replicate samples or among the different patients in group 1 . All values were significantly different from normal values. All the other patients (groups 2 and 3) had normal values for the percentage of type III collagen in their lungs, regardless of ventilator history, other lung disease, inspired concentration of oxygen, or smoking history. Histologically, the four patients with adult respiratory distress syndrome all showed evidence of interstitial fibrosis whereas none of the other subjects studied had histologically discernible interstitial fibrosis.

Lung collagen concentrations and wet-to-dry weight ratios are shown in table 3 . These data are derived from single samples in each patient and are too few to permit firm conclusions but they suggest that there may be an increase in lung collagen in the adult respiratory distress syndrome.

\section{Discussion}

Although the ratios of collagen types in various organs change during fetal and neonatal development, they seem to remain remarkably constant during adult life. Shifts in the ratios have been reported, in association with serious dysfunction in several organs. For example, changes have been described in bone (from patients with osteogenesis imper- 
fecta) ${ }^{18}$ cirrhotic liver, ${ }^{19}$ atherosclerotic blood vessels, ${ }^{20}$ prolapsed mitral valve, ${ }^{21}$ and rheumatoid synovia. ${ }^{22}$ Changes in collagen type ratios have also been documented in lung. Seyer et al $^{14}$ showed that lungs from patients with idiopathic pulmonary fibrosis had significantly lower ratios of type III to type I collagen than did lungs from normal patients.

In this report we have shown that patients with clinical and histopathological evidence of the adult respiratory distress syndrome had significant decreases in the relative amount of type III collagen in their lungs. These findings in acutely fibrotic lungs are thus similar to the findings of Seyer et al in chronically fibrotic lungs. ${ }^{14}$ Our results are also consistent with the report of Zapol and his colleagues that the collagen content of lungs from patients with adult respiratory distress syndrome is about doubled in patients whose illness was of 11 to 16 days' duration. ${ }^{5}$ If all this newly synthesised collagen had been type I the ratio of collagen types in the lung would have changed from $2: 1$ (33\% type III) to $5: 1$ (16.5\% type III). Our results (table 2) suggest that if the patients we studied were on average as ill as those of Zapol et al at least $85 \%$ of the newly synthesised collagen in their lungs must have been of type I. Such a result is consistent with the values we have observed ${ }^{11}$ for changes in the ratios of types I and III collagen being synthesised by lungs of rats exposed to various fibrogenic stimuli (80-83\% type I).

We found no evidence of a shift in collagen types in any of the patients not suffering from the adult respiratory distress syndrome, including several with lung disease who had been on ventilators, though it is important to note that group 2 patients all spent less time on a ventilator (three to eight days) than did the group 1 patients. Our data suggest that the stimulus for the shift in lung collagen types observed in this study is a fairly specific event - that is, such general insults to the lung as underlying disease other than adult respiratory distress syndrome and ventilator support for a few days with high positive end-expiratory pressures or high partial pressures of oxygen may not be sufficient to initiate the process. On the other hand, the potential interactions of oxygen treatment and ventilator support with the underlying disease process in the adult respiratory distress syndrome remain to be defined. Another unanswered question is whether the pattern of abnormal collagen deposition in the lungs of patients with the adult respiratory distress syndrome described by Zapol $e t a^{\mathbf{s}}$ and by us in the present study is reversible or irreversible. Since lung function is thought to return to normal in survivors, ${ }^{15}$ either the survivors are a selected population whose lung collagen metabolism does not change or the changes may be reversible on recovery (given that the functional tests reflect the structural change). Animal models may help to throw light on the natural history of the adult respiratory distress syndrome and may also prove useful in the assessment of potential antifibrotic drugs. ${ }^{612}$

We thank Drs Joseph Cummiskey, James Holcroft, Murray Gardiner, and Henry Tesluk for their assistance in the acquisition of lung tissue and Suzanne Williams for skilled technical assistance. This work was supported in part by National Institutes of Health grants HL-26620, ES-00628, and RR00169. Dr Reiser was supported by a Young Investigator Award from the National Institutes of Health (HL-26795).

\section{References}

${ }^{1}$ Nash G, Blennerhassett JB, Pontoppidan H. Pulmonary lesions associated with oxygen therapy and artificial ventilation. N Engl J Med 1967;276:368-74.

2 Pratt PC, Vollmer RT, Shelburne JD, Crapo JD. Pulmonary morphology in a multihospital collaborative extracorporeal membrane oxygenation project. I. Light microscopy. Am J Pathol 1979;95:191-214.

${ }^{3}$ Katzenstein AA, Bloor CM, Leibow AA. Diffuse alveolar damage - the role of oxygen, shock, and related factors. Am J Pathol 1976;85:210-22.

${ }^{4}$ Simmons DH, Nash G, Brigham KL, et al. Adult respiratory distress syndrome-interdepartmental clinical case conference. West J Med 1979;130:21835.

5 Zapol WM, Trelsted RL, Coffey JW, Tsai I, Salvador RA. Pulmonary fibrosis in severe acute respiratory failure. Am Rev Respir Dis 1979;119:547-54.

- Zapol WM, Mark EJ. Clinicopathological conference. $N$ Engl J Med 1977;296:1279-87.

${ }^{7}$ Crystal RG, Fulmer JD, Roberts WC, Moss ML, Line BR, Reynolds HY. Idiopathic pulmonary fibrosis. Ann Intern Med 1976;85:769-88.

${ }^{8}$ Snider GL, Hayes JA, Korthy AL. Chronic interstitial pulmonary fibrosis produced in hamsters by endotracheal bleomycin: pathology and stereology. Am Rev Respir Dis 1978;117:1099-108.

- Starcher BC, Kuhn C, Overton JE. Increased elastin and collagen content in the lungs of hamsters receiving an intratracheal injection of bleomycin. Am Rev Respir Dis 1978;117:299-305.

${ }^{10}$ Greenberg DB, Reiser KM, Last JA. Correlation of biochemical and morphological manifestations of acute pulmonary fibrosis in rats administered paraquat. Chest 1978;74:421-5.

1 Reiser KM, Last JA. Pulmonary fibrosis in experimental acute respiratory disease. Am Rev Respir Dis 1981;123:58-63.

12 Hesterberg TW, Last JA. Ozone-induced acute pulmonary fibrosis in rats. Prevention of increased rates of collagen synthesis by methylprednisolone. Am Rev Respir Dis 1981;123:47-52.

${ }^{13}$ Last JA, Greenberg DB. Ozone-induced alterations in 
collagen metabolism of rat lungs. II-Long-term exposures. Toxicol Appl Pharmacol 1980;55:108-14.

${ }^{14}$ Seyer JM, Hutcheson ET, Kang AH. Collagen polymorphism in idiopathic chronic pulmonary fibrosis. J Clin Invest 1976;57:1498-507.

${ }^{15}$ Hempel FG, Lenfant CJM. Current and future research on adult respiratory distress syndrome. Sem Respir Med 1981;ii:165-72.

${ }^{16}$ Reiser KM, Last JA. Quantitation of specific collagen types from lungs of small mammals. Anal Biochem 1980;104:87-98.

${ }^{17}$ Woessner JF Jr. The determination of hydroxyproline in tissue and protein samples containing small proportions of this imino acid. Arch Biochem Biophys 1961;93:440-7.

${ }^{18}$ Muller PK, Raisch K, Matzen K, Gay S. Presence of type III collagen in bone from a patient with osteogenesis imperfecta. Europ J Pediat 1977;125:29-37.

${ }^{19}$ Seyer JM, Hutcheson ET, Kang AG. Collagen polymorphism in normal and cirrhotic human liver. $J$ Clin Invest 1977;59:241-8.

${ }^{20}$ McCullagh KA, Balian G. Collagen characterization and cell transformation in human atherosclerosis. Nature 1975;258:73-5.

${ }^{21}$ Hammer D, Leier CV, Baba N, Vasko JS, Wooley CR, Pinnell SR. Altered collagen composition in a prolapsing mitral valve with ruptured chordae tendineae. Am J Med 1979;67:863-6.

${ }^{22}$ Weiss JB, Shuttleworth CA, Brown R, Sedowfia K, Baildam A, Hunter JA. Occurrence of type III collagen in inflamed synovial membranes: a comparison between non-rheumatoid rheumatoid, and normal synovial collagens. Biochem Biophys Res Commun 1975;65:907-12. 